
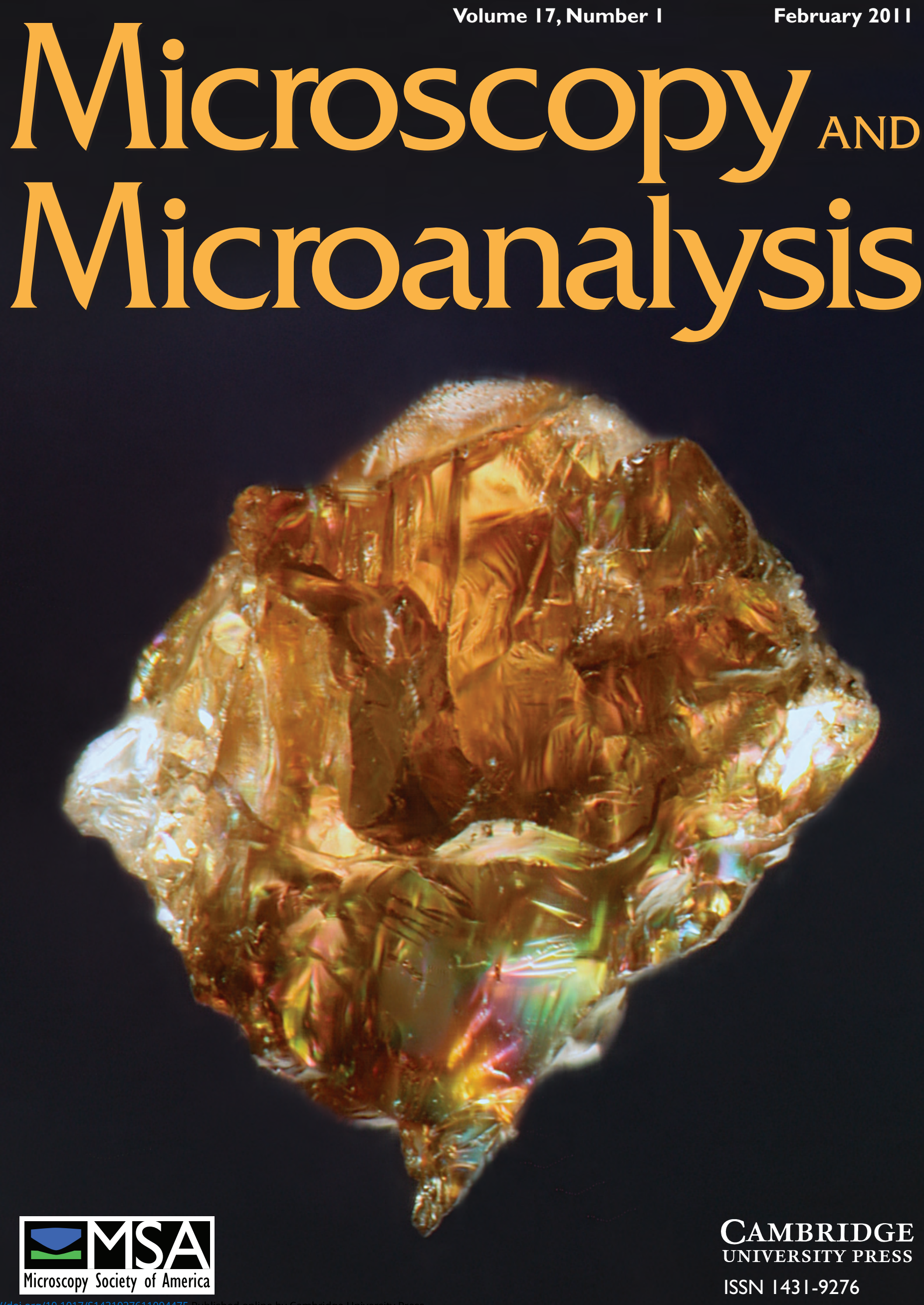



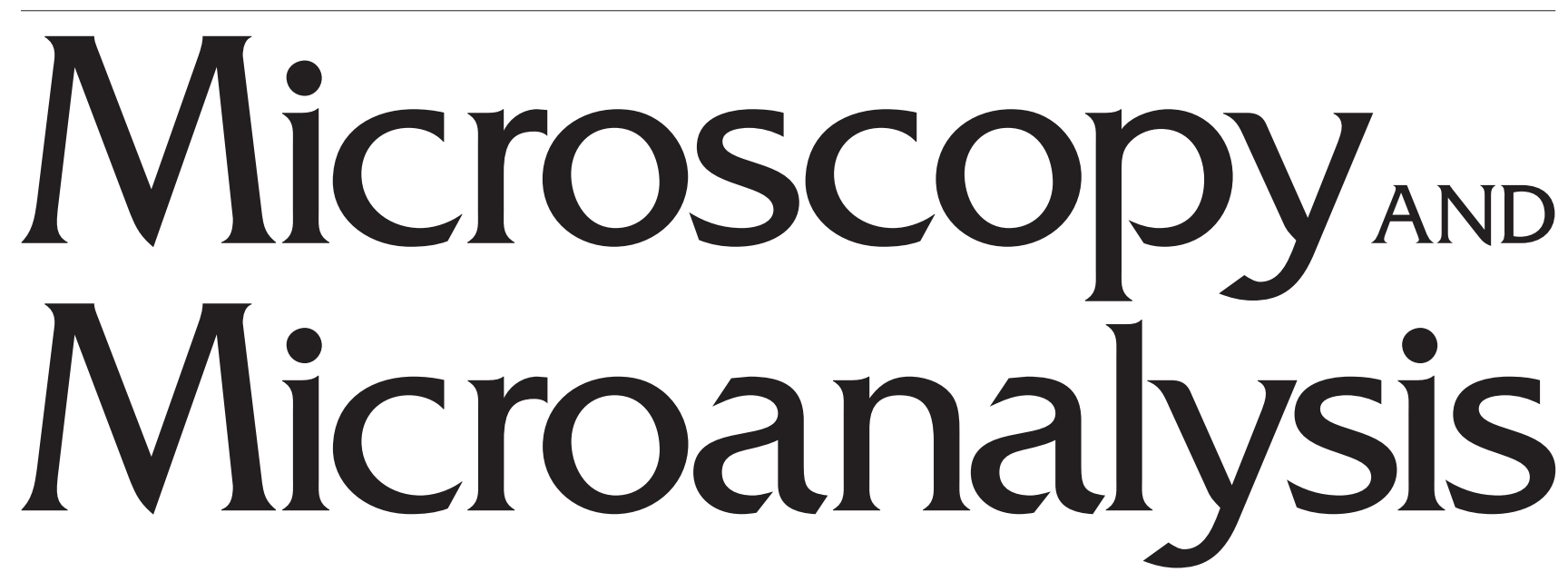

An International Journal for the Biological and Physical Sciences

THE OFFICIAL JOURNAL OF

PUBLISHED IN AFFILIATION WITH

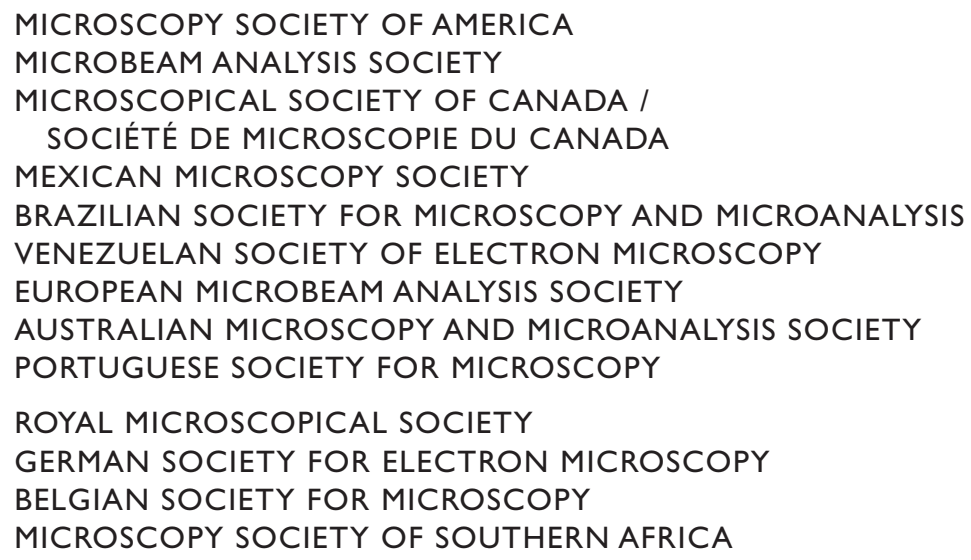

\section{Editor in Chief}

Editor, Biological Applications Robert L. Price

Cell and Developmental Biology and Anatomy

University of South Carolina

Columbia, SC 29209

e-mail: Bob.Price@uscmed.sc.edu

Editor, Materials Applications

David J. Smith

Department of Physics

School of Materials

Arizona State University

Tempe, Arizona 85287-1504

e-mail: david.smith@asu.edu

Editor, Scanning Probe

Microscopies

Phillip Russell

Physics and Astronomy

Appalachian State University

Boone, North Carolina 28608

e-mail: russllp@appstate.edu

\section{Editor, Atom Probe}

Thomas Kelly

Cameca Instruments, Inc.

A Business Unit of AMETEK, Inc.

Madison, WI 53711-4951

e-mail: Thomas.Kelly@ametek.com
Editor, Light and Fluorescence Microscopies

Brian Herman

Cellular and Structural Biology

University of Texas at San Antonio

San Antonio, Texas 78284-7762

e-mail: hermanb@uthscsa.edu

Editor, Biological Applications Heide Schatten

Veterinary Pathobiology

University of Missouri-Columbia

Columbia, Missouri 65211-5030

e-mail: schattenh@missouri.edu

Editor, Microanalysis

John Mansfield

Electron Microbeam Analysis Lab

North Campus, 417 SRB

University of Michigan

Ann Arbor, MI 48109-2143

e-mail: jfmjfm@umich.edu

Editor, Correlative and Emerging Microscopy Applications

Vinayak P. Dravid

Materials Science and Engineering

Northwestern University

Evanston, Illinois 60208-3105

e-mail: v-dravid@northwestern.edu
Special Issues and Reviews Editor Jay Jerome

Vanderbilt University Medical Center

Nashville, TN 37232

e-mail: jay.jerome@vanderbilt.edu

Book Review Editor

Cynthia S. Goldsmith

Centers for Disease Control

Atlanta, GA 30333

e-mail: csg1@cdc.gov

\section{Calendar Editor}

Nan Yao

Princeton University

Princeton, NJ 08540

e-mail: nyao@Princeton.edu

\section{Expo Editor}

Richard E. Edelmann

Miami University

Oxford, OH 45056

e-mail: edelmare@muohio.edu

\section{Proceedings Editor}

John Shields

University of Georgia

Athens, GA 30602

e-mail: jpshield@uga.edu 


\section{Editorial Board}

\author{
Ralph Albrecht \\ Barry Carter \\ Wah Chiu \\ Niels de Jonge \\ Elizabeth Dickey \\ Alwyn Eades \\ Mark Ellisman \\ Pratibha Gai \\ Marija Gajdardziska-Josifovska \\ Dale Johnson \\ Paul Kotula \\ William Landis \\ Eric Lifshin \\ Charles Lyman \\ Dale Newbury \\ Jean-Paul Revel \\ Conly Rieder \\ John Silcox \\ Nestor Zaluzec
}

University of Wisconsin, Madison, Wisconsin

University of Connecticut, Storrs, Connecticut

Baylor College of Medicine, Houston, Texas

Vanderbilt University School of Medicine

Pennsylvania State University, University Park, Pennsylvania

Lehigh University, Bethlehem, Pennsylvania

University of California at San Diego, San Diego, California

University of York, United Kingdom

University of Wisconsin-Milwaukee, Milwaukee, Wisconsin

University of South Florida, Tampa, Florida

Sandia National Labs, Albuquerque, New Mexico

Northeastern Ohio Universities College of Medicine, Rootstown, Ohio

SUNY at Albany, Albany, New York

Lehigh University, Bethlehem, Pennsylvania

National Institute of Standards and Technology, Gaithersburg, Maryland

California Institute of Technology, Pasadena, California

Wadsworth Center, Albany, New York

Cornell University, Ithaca, New York

Argonne National Laboratory, Argonne, Illinois

\section{Editorial Board Representatives from Affiliated Societies}

Ian Anderson

Gema Gonzalez

Michael Robertson

Brendan Griffin

Guillermo Solorzano

Clive Walker

Miguel Yacaman

Henrique Almeida
NIST, Gaithersburg, Maryland (MAS)

Venezuelan Institute for Scientific Investigation (Venezuela)

Acadia University, Wolfville, Nova Scotia (Canada)

University of Western Australia (AMMS)

Pontificia Universidade Catolica, Rio de Janeiro (Brazil)

Institute for Transuranium Elements, Karlsruhe (EMAS)

Mexico Institute for Nuclear Research (Mexico)

Universidade do Porto (Portugal)

\section{Founding Editor}

Jean-Paul Revel

\section{Previous Editors-in-Chief}

Dale Johnson

Charles Lyman
University of South Florida, Tampa, Florida

Lehigh University, Bethlehem, Pennsylvania

This journal is part of the Cambridge Journals Online service. Access to online tables of contents and article abstracts is available to all researchers at no cost. Access to full-text articles online is provided to those with online subscription. Online subscriptions must be activated. Once your subscription is activated, free access to past, present, and forthcoming articles is available at:

\section{Microscopy and Microanalysis website: journals.cambridge.org/MAM.}

Instructions for authors submitting manuscripts may be found at journals.cambridge.org/MAM. Select "Further Information" then select "Instructions for Contributors." An abbreviated version of these instructions will be published in the first issue (February) of each volume. 


\section{나로듀

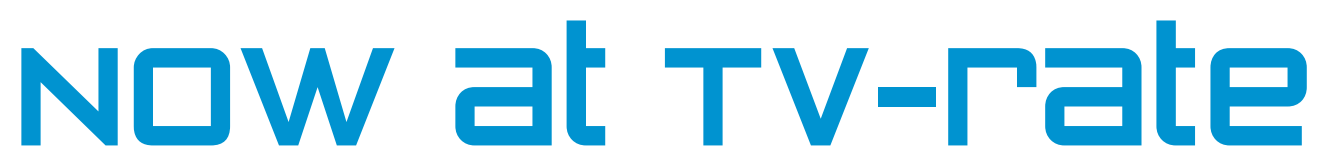

UltraScan ${ }^{\otimes} 1000 X P$ The benchmark re-ınvented

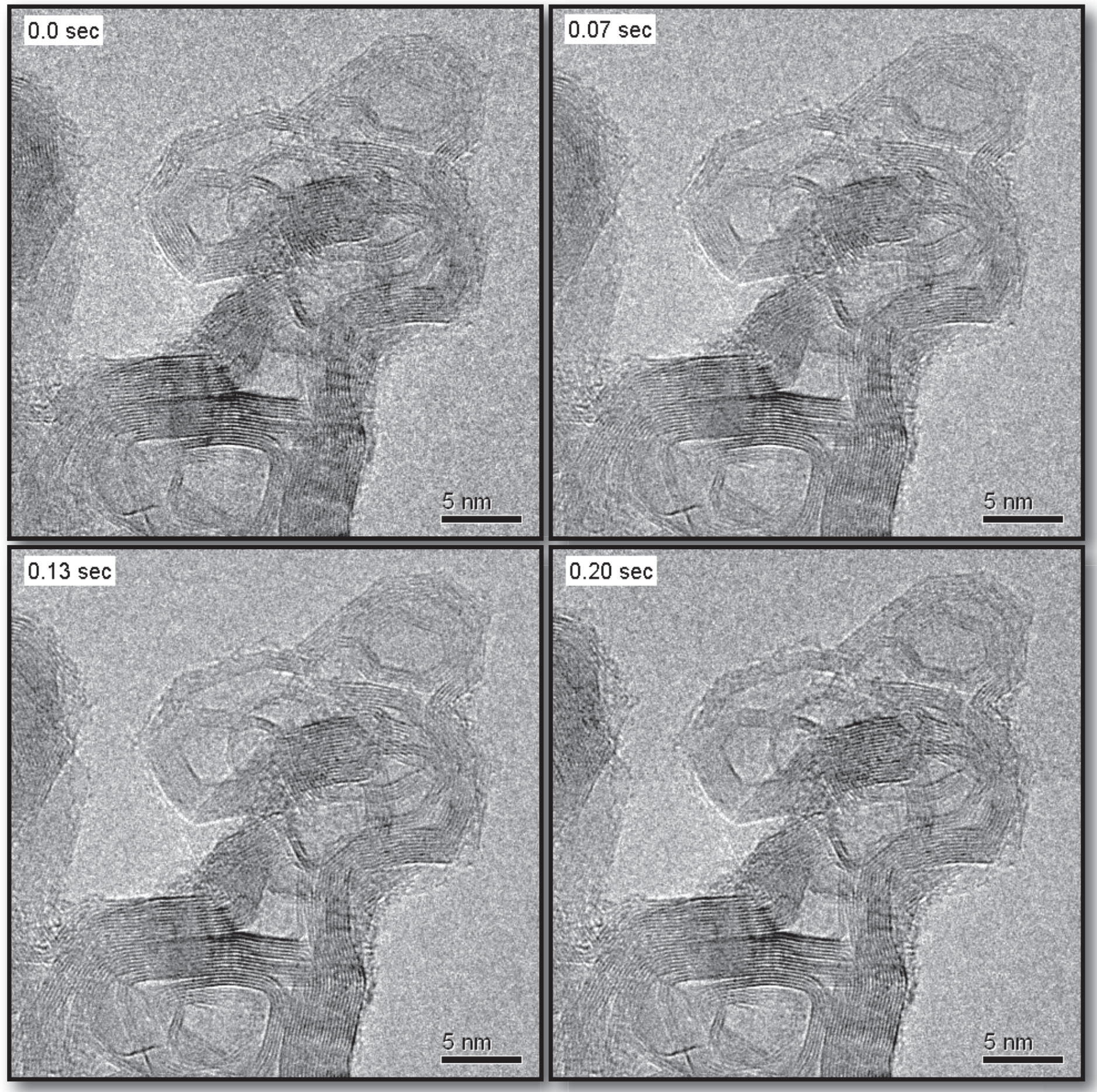

Individual frames of a captured digital streaming video sequence of graphitized carbon sample with Gatan UltraScan ${ }^{\circledR} 1000 \mathrm{XP}$ CCD camera on a $200 \mathrm{kV}$ TEM. The camera was operated at $16 \mathrm{fps}$. TEM magnification $=400 \mathrm{kx}$. 
Microscopy and Microanalysis publishes original research papers dealing with a broad range of topics in microscopy and microanalysis. These include articles describing new techniques or instrumentation and their applications, as well as papers in which established methods of microscopy or microanalysis are applied to important problems in the fields of biology or materials science. Microscopy and microanalysis are defined here in a broad sense, and include all current and developing approaches to the imaging and analysis of microstructure. The criteria for acceptance of manuscripts are the originality and significance of the research, the quality of the microscopy or microanalysis involved, and the interest for our readership.

Four types of communications are published in the Journal. Regular Articles are of substantial length and describe the findings of an original research project that satisfies the aims and scope of the Journal, described above. Review Articles summarize the current status of an important area within the aims and scope of the Journal. Letters to the Editor usually contain comments on recent articles that have appeared in the Journal. Book Reviews are also published, but these are solicited only through the Book Review Editor.

\section{Instructions for Contributors}

Instructions for authors contributing manuscripts may be found at http://mc.manuscriptcentral.com/mam under "Resources: Instructions and Forms." Authors may also visit http://www.journals.cambridge.org/ jid_MAM, select "Further Information," and then select "Instructions for Contributors." An abbreviated version of these instructions will be published in the first issue (February) of each volume.

\section{Copyright Information}

Submission of a manuscript implies: that the work described has not been published before (except in the form of an abstract or as part of a published lecture, review, or thesis); that it is not under consideration for publication elsewhere; that its publication has been approved by all coauthors, if any, as well as by the responsible authorities at the institute where the work has been carried out; that, if and when the manuscript is accepted for publication, the authors agree to automatic transfer of the copyright to the Microscopy Society of America; that the manuscript will not be published elsewhere in any language without the consent of the copyright holders; and that written permission of the copyright holder is obtained by the authors for material used from other copyrighted sources.

All articles published in this journal are protected by copyright, which covers the exclusive rights to reproduce and distribute the article (e.g., as offprints), as well as all translation rights. No material published in this journal may be reproduced photographically or stored on microfilm, in electronic data bases, video disks, etc., without first obtaining written permission from the publisher.

The use of general descriptive names, trade names, trademarks, etc., in this publication, even if not specifically identified, does not imply that these names lack protection by the relevant laws and regulation.

Authorization to photocopy items for internal or personal use, or the internal or personal use of specific clients, is granted by Cambridge University Press, provided that the appropriate fee is paid directly to Copyright Clearance Center, 222 Rosewood Drive, Danvers, MA 01923 , USA (Tel: (508) 750-8400), stating the ISSN (1431-9276), the volume, and the first and last page numbers of each article copied. The copyright owner's consent does not include copying for general distribution, promotion, new works, or resale. In these cases, specific written permission must first be obtained from the publisher.

\section{Disclaimer}

The Microscopy Society of America, the other societies stated, and Cambridge University Press cannot be held responsible for errors or for any consequences arising from the use of the information contained in this journal. The appearance of scientific reports and/or workshops, or any other material in Microscopy and Microanalysis does not constitute an endorsement or approval by The Microscopy Society of America of the findings, data, conclusions, recommendations, procedures, results, or any other aspect of the content of such articles. The appearance of advertising in Microscopy and Microanalysis does not constitute an endorsement or approval by The Microscopy Society of America of the quality or value of the products advertised or any of the claims, data, conclusions, recommendations, procedures, results, or any other information included in the advertisements.

While the advice and information in this journal is believed to be true and accurate at the date of its going to press, neither the authors, the editors, nor the publisher can accept any legal responsibility for any errors or omissions that may be made.

\section{Subscription Information}

Microscopy and Microanalysis is published bimonthly in February, April, June, August, October, and December by Cambridge University Press. Two supplements (Expo and Proceedings) are published in June and August.

Society Rates: Members of the Microscopy Society of America should contact the MSA Business Office for all subscription inquiries: Microscopy Society of America, Hachero Hill, Inc., 11260 Roger Bacon Drive, Suite 402, Reston, VA 20190, Tel.: (703) 964-1240, Ext. 14, E-mail: nicoleguy@mindspring.com, URL: www.msa.microscopy.org. Members of other affiliated societies should contact their respective society business offices for all subscription inquiries.

Subscription Rates: Institutions print and electronic: US \$957.00 in

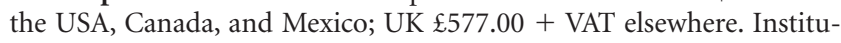
tions online only: US $\$ 790.00$ in the USA, Canada, and Mexico; UK $£ 478.00+$ VAT elsewhere. Institutions print only: US $\$ 863.00$ in the USA, Canada, and Mexico; UK $£ 520.00+$ VAT elsewhere. Individuals print and online: US $\$ 359.00$ in the USA, Canada, and Mexico; UK

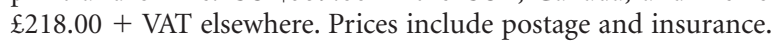

USA, Canada, and Mexico: Subscribers in the USA, Canada, and Mexico should send their orders, with payment in US dollars or the equivalent value in Canadian dollars, to: Cambridge University Press, Customer Services Department (Journals), 100 Brook Hill Drive, West Nyack, NY 10994-2133, USA. Tel: (845) 353-7500. Fax: (845) 353-4141. Orders may be phoned direct (toll free): (800) 872-7423. E-mail: journals_subscriptions@cup.org.

Outside North America: Subscribers elsewhere should send their orders, with payment in sterling, to: Customer Services Department (Journals), Cambridge University Press, The Edinburgh Building, Shaftesbury Road, Cambridge, CB2 8RU, UK. Tel: +44 (0)1223 326070. Fax: +44 (0)1223 325150. E-mail: journals@cambridge.org

Change of address: Allow six weeks for all changes to become effective. All communications should include both old and new addresses (with postal codes) and should be accompanied by a mailing label from a recent issue. Society members should contact their respective society business offices to inform them of address changes.

Microform editions are available from: University Microfilms International, 300 North Zeeb Road, Ann Arbor, MI 48106, USA.

\section{Editorial Office}

Robert L. Price, Editor in Chief, Department of Cell and Developmental Biology and Anatomy, School of Medicine, University of South Carolina, 6439 Garner's Ferry Road, Bldg. 1 B-60, Columbia, SC 29209, USA; Tel: (803) 733-3392; Fax: (803) 733-3212; E-mail: Bob.Price@uscmed.sc.edu.

\section{Office of Publication}

Cambridge University Press, 32 Avenue of the Americas, New York, NY 10013-2473, USA; Tel: (212) 337-5000; Fax: (212) 337-5959.

\section{Advertising Sales \& Production}

M.J. Mrvica Associates, Inc., 2 West Taunton Avenue, Berlin, NJ 08009, USA; Tel: (856) 768-9360; Fax: (856) 753-0064.

(C) 2011 by Microscopy Society of America. Printed in the United States on acid-free paper. Periodicals postage paid at New York, NY, and additional mailing offices. Return postage guaranteed. Postmaster: Send address changes in the U.S.A. and Canada to Microscopy and Microanalysis, Subscription Department, Cambridge University Press, 100 Brook Hill Drive, West Nyack, NY 10994-2133. 


\section{Side-By-Side Comparison? Difficult When Our Coaters Stand Alone.}

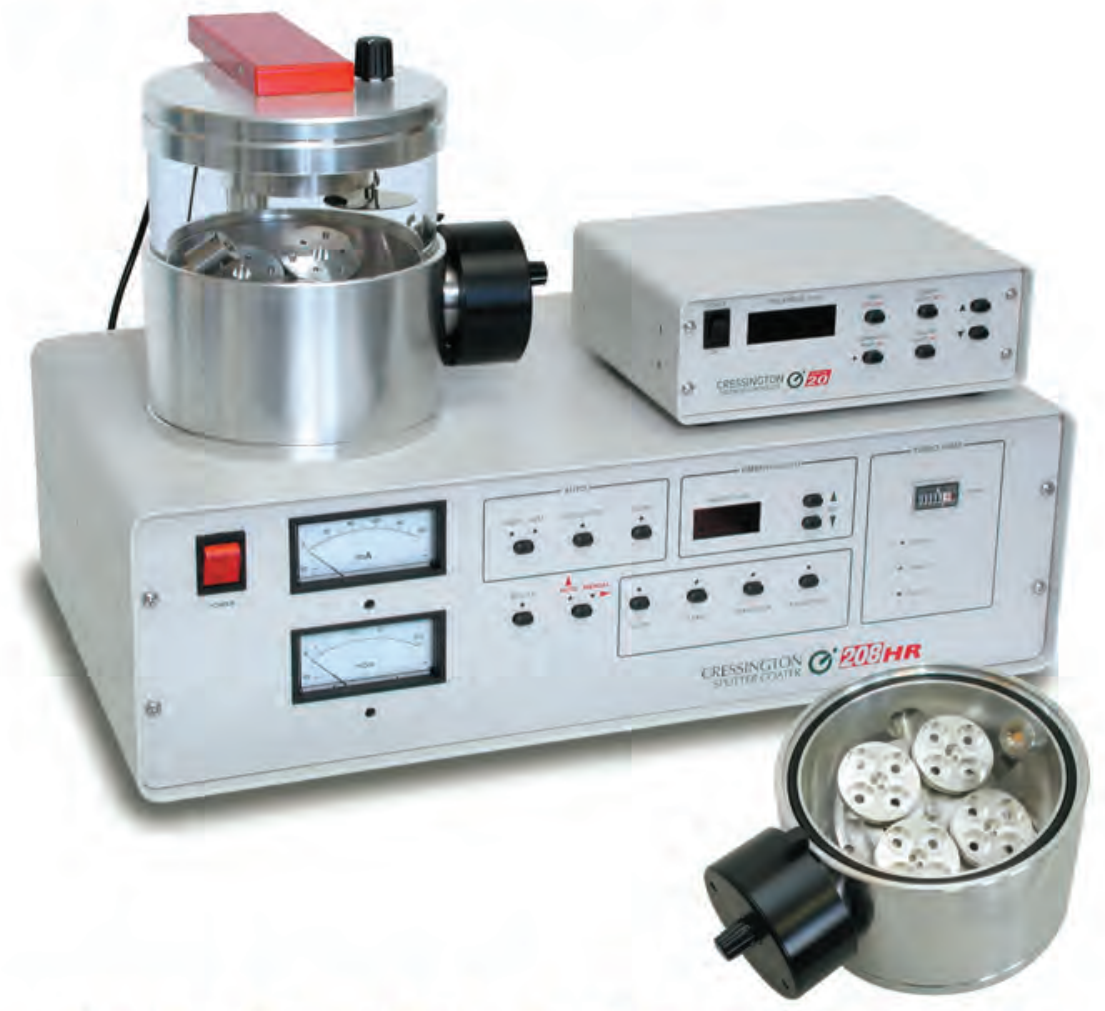

\section{High Resolution Sputter Coater}

\section{HR for FE-SEM}

\section{Superior Features:}

- High Resolution Fine Coating

- Wide Choice of Coating Materials

- High Resolution Thickness Control

- Multiple Sample Stage Movements

- Wide Range of Operating Pressures

- Compact, Modern, Benchtop Design
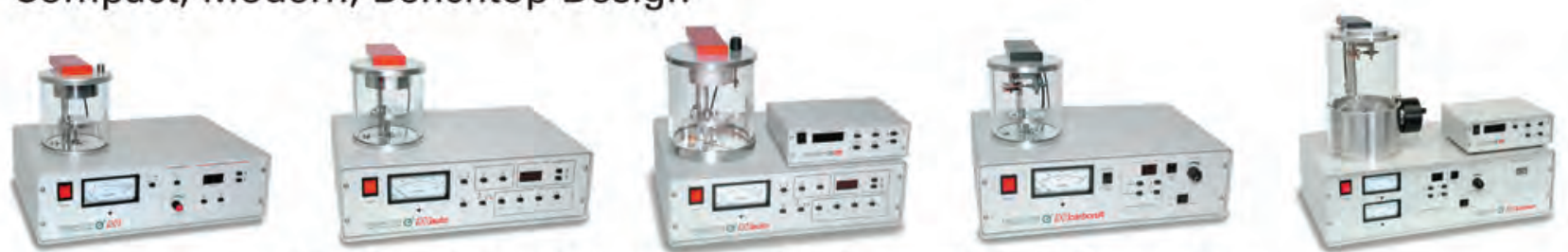

Find out about our complete line of sample coaters.

7 TED PELLA, INC. Microscopy Products for Science and Industry
4595 Mountain Lakes Blvd., Redding, CA 96003-1448

Phone: $530-243-2200$ or 800-237-3526 (USA) FAX: 530-243-3761

Email: sales@tedpella.com Web Site: www.tedpella.com 


\section{SPI Supplies.}

The complete source for all your microscopy needs...

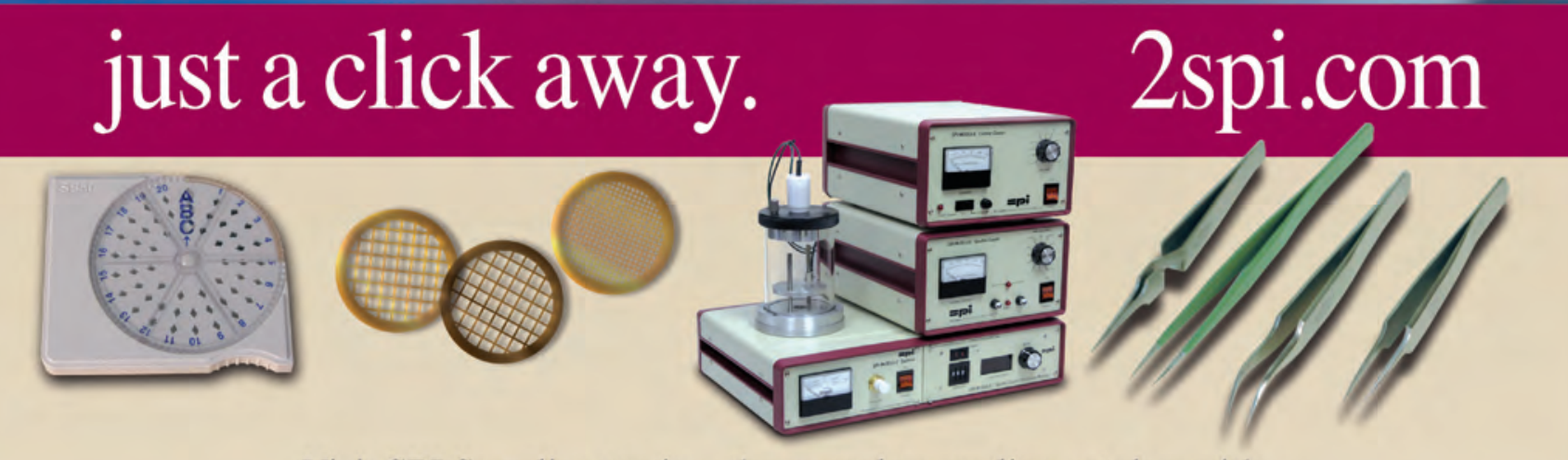

Visit SPI Supplies to view the complete on-line catalog with

up-to-the-minute product and pricing information.

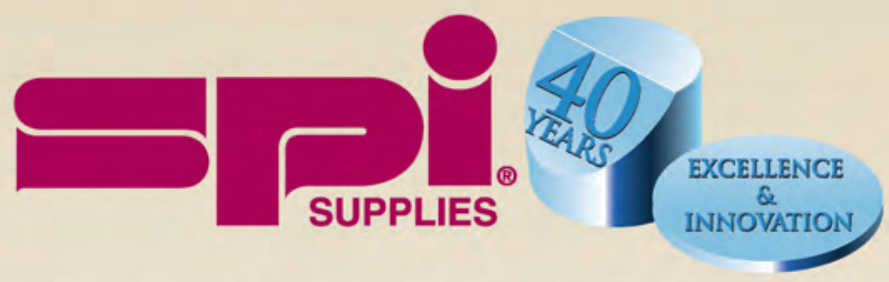

SPI Supplies Division of STRUCTURE PROBE, Inc.

P.0. Box $656 \bullet$ West Chester, PA 19381-0656 USA

Phone: 1-610-436-5400 • 1-800-2424-SPI (USA and Canada) • Fax: 1-610-436-5755• E-mail: sales@2spi.com 


\section{Microscopy $_{\text {AND }}$ Microanalysis}

An International Journal for the Biological and Physical Sciences

Volume 17, Number I

February $201 \mathrm{I}$

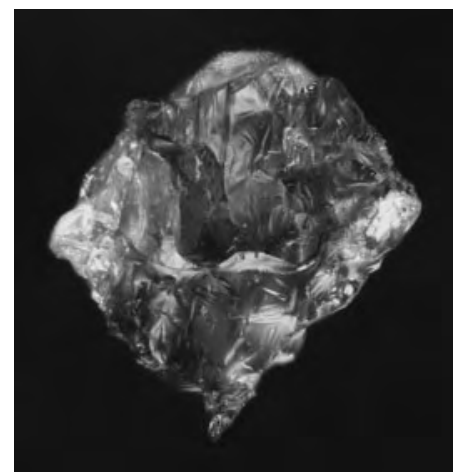

On the Cover: Optical micrograph of lunar regolith particle. For further information see Kiely et al. pp. 34-48.

\section{Atom Probe Applications}

\section{Review Article}

Kinetic Energy Discrimination for Atom Probe Tomography

Thomas F. Kelly

On the Field Evaporation Behavior of Dielectric Materials in Three-Dimensional Atom Probe: A Numeric Simulation

Christian Oberdorfer and Guido Schmitz

Critical Consideration of Precipitate Analysis of $\mathrm{Fe}-1$ at.\% $\mathrm{Cu}$ Using Atom Probe and Small-Angle Neutron Scattering

M. Schober, E. Eidenberger, P. Staron, and H. Leitner

\section{Cover Article}

A New Look at Lunar Soil Collected from the Sea of Tranquility during the Apollo 11 Mission

Carol Kiely, Gary Greenberg, and Christopher J. Kiely

\section{TEM and Stem Materials Applications}

Dislocation Associated Incubational Domain Formation in Lightly Gadolinium-Doped Ceria

Zhi-Peng Li, Toshiyuki Mori, Fei Ye, Ding Rong Ou, Jin Zou, and John Drennan

Characterization of Mesoporosity in Ceria Particles Using Electron Microscopy

Shao-Ju Shih, Pilar Rodrigo Herrero, Guoqiang Li, Chin-Yi Chen, and Sergio Lozano-Perez

Quantitative Analysis of Particle Distributions by Comparison with Simulations Sascha Vongehr, Shaochun Tang, and Xiangkang Meng

Variable Resolution Fluctuation Electron Microscopy on Cu-Zr Metallic Glass Using a Wide Range of Coherent STEM Probe Size

Jinwoo Hwang and P.M. Voyles

Extended Depth of Field for High-Resolution Scanning Transmission Electron Microscopy

Robert Hovden, Huolin L. Xin, and David A. Muller

\section{Biological Applications}

Speckle Patterning of Soft Tissues for Strain Field Measurement Using Digital Image Correlation: Preliminary Quality Assessment of Patterns Jinfeng Ning, Vaughn G. Braxton, Ying Wang, Michael A. Sutton, Yanqing Wang, and Susan M. Lessner 
Expression and Deposition of Fibrous Extracellular Matrix Proteins in Cardiac Valves during Chick Development

Hong Tan, Lorain Junor, Robert L. Price, Russell A. Norris, Jay D. Potts, and Richard L. Goodwin

New Viruses from Lacerta monticola (Serra da Estrela, Portugal): Further Evidence for a New Group of Nucleo-Cytoplasmic Large Deoxyriboviruses

António Pedro Alves de Matos, Maria Filomena Alcobia da Silva Trabucho Caeiro, Tibor Papp, Bruno André da Cunha Almeida Matos, Ana Cristina Lacerda Correia, and Rachel E. Marschang

Morphological Confocal Microscopy in Arthropods and the Enhancement of Autofluorescence after Proteinase K Extraction

Antonio G. Valdecasas and Angela Abad

Using Microscopy to Assess Chorion Structural Integrity and Parasitoid Oviposition Sites on Stink Bug (Hemiptera: Pentatomidae) Eggs

A.L. Koppel, D.A. Herbert, Jr., and E.W. Westbrook

Micromorphology of Epicuticular Waxes and Epistomatal Chambers of Pine Species by Electron Microscopy and White Light Scanning Interferometry

Ki Woo Kim, In Jung Lee, Chang Soo Kim, Don Koo Lee, and Eun Woo Park

Microphotometry of Underwater Shadowing by a Moss from a Niagara Escarpment Waterfall

Howard J. Swatland

\section{B OOK REVIE W}

Scanning Tunneling Microscopy in Surface Science, Nanoscience and Catalysis, Michael Bowker and Philip R. Davies (Eds.)

Yabing Qi

\section{Calendar of Meetings and Courses}


Microscopy and Microanalysis is published bimonthly and contains papers that report original research from the entire interdisciplinary range of microscopy and microanalysis: new microscopy methods and instrumentation and their applications to biological or materials microstructures for determination of structure or chemistry. Four categories of communications are published in the Journal.

Regular articles contain reports of new instrumentation and new methods and their applications to microstructural analysis in biology and materials science. Reviews have broader technical content than regular articles. Authors contemplating review articles are encouraged to discuss their plans with the appropriate editor. Articles are accepted for publication with the understanding that they, or their substantive contents, have not been and will not be submitted to any other publication.

Readers may send Letters to the Editor for publication in the Journal. These must address a specific technical point or points in a published article and must be clearly written and concise. The corresponding author of the paper commented upon will be invited to reply. The author of the Letter to the Editor will not be sent the reply prior to publication. Both the Letter to the Editor and the Reply will be published together. No subsequent letters or replies by the same persons concerning that particular paper will be considered for publication. The Editor-in-Chief will make any necessary decisions concerning suitability for publication of particular Letters to the Editor or Replies. Book Reviews are also published, but these are solicited only through the Book Review Editor.

\section{Manuscript Submission and Review}

All manuscript submissions to Microscopy and Microanalysis must be made electronically via Manuscript Central, at the following website address:

\section{http://mc.manuscriptcentral.com/mam}

Complete instructions are provided on this website. Please follow the instructions on the website to avoid delays. The instructions will prompt the author to provide all necessary information, including the corresponding author's contact information, which includes complete mailing address, phone and fax numbers, and an e-mail address. The website also requests suggested reviewers.

The website will automatically acknowledge receipt of the manuscript and provide a manuscript reference number. The Editor-in-Chief will assign the manuscript to an Editor who will choose at least two other reviewers. Every effort will be made to provide the author with a rapid review. If the Editor requests that revisions be made to the manuscript before publication, a maximum of 3 months will be allowed for preparation of the revision.

\section{Manuscript Preparation}

General information. Manuscripts should be formatted in Word. However, if there is a considerable amount of math, LaTeX can be used, but a PDF version of the manuscript must be supplied as well. Manuscripts must be submitted in English. Authors should follow generally accepted rules of grammar and punctuation. Because articles on microscopy attract broad ranges of readers with diverse backgrounds, jargon should not be used; acronyms and abbreviations must be clearly defined the first time they are used and then used consistently thereafter throughout the manuscript.
Format. All manuscripts must be typed double-spaced, including title page, abstract, text, references, tables, and figure legends, in 12 point type. Pages should have margins of about 1 inch (about $2.5 \mathrm{~cm}$ ). Pages should be numbered at the bottom center.

All manuscript title pages must contain:

- A complete title.

- A brief title to be used as a running head.

- Authors' names listed by full given and last names.

- Primary institutions where the research was performed.

- Other institutions involved for each author.

- Permanent or new addresses of all authors. Note: Institutional addresses must include the full institutional and department/center name, city, state, postal code, and country.

- A complete corresponding (mailing) address for the author to whom all correspondence should be sent.

- Corresponding author's telephone number, fax number, and e-mail address.

All manuscripts must include:

- An abstract not to exceed 200 words and 6 to 10 keywords for indexing.

- The following sections: Introduction, Materials and Methods, Results, Discussion, Conclusions, Acknowledgments, References, tables, figure legends, figures. Sections may be subdivided to increase clarity.

Chemical names and mathematical expressions. Chemical names and methods should be spelled out the first time they are used, followed by the abbreviation in parentheses. After first mention the abbreviation may be used alone. SI units should be used. Mathematical expressions need to be carefully presented, with all symbols defined. Use a type font that clearly differentiates between zero and capital letter O. Equations containing algebraic fractions should use numerator over denominator, separated by a horizontal line, and not typed on a single line separated by a slash. Indicate vector symbols; they will be printed in bold.

References. References must be inserted in the text at the place they are used, by the author's surname and year of publication. All references included in the reference list must be cited in the text. References to personal communications, unpublished data, and manuscripts either in preparation or submitted for publication are unacceptable. If essential, such material may be incorporated in the appropriate place in the text. For citations with more than two authors use the first author's surname followed by "et al." and if there is more than one reference in the same year by a single author(s), use $a, b$. For example: (Roberts, 1981); (Roberts \& Johnson, 1983); (Jones et al., 1986); (Johnson, 1998a, 1998b).

All authors must be included in the reference list; "et al." is unacceptable here. The alphabetical list of references begins a new page and must be typed double-spaced. List works by different authors who are cited within the same parentheses in chronological order, beginning with the earlier work according to the CBE Manual for Authors, Editors, and Publishers. Abbreviate journal names according to the Chemical Abstracts Service Source Index (CASSI). Only published articles and articles in press should appear in this list. Responsibility for the accuracy of references cited lies with the authors. Brief examples: 


\section{Journal Articles}

Hogan, J. \& Patton, C. (1976). Variation in intramembrane components of Trypanosoma brucei from intact and X-radiated rats: A freeze-cleave study. J Protozool 23, 205-215.

\section{Entire Book}

Rappaport, R. (1996). Cytokinesis in Animal Cells. Cambridge, UK: Cambridge University Press.

\section{Chapter in an Edited Book}

Gardner, R.L. \& Papaioannou, V.E. (1975). Differentiation in trophectoderm and inner cell mass. In The Early Development of Mammals, Balls, M. \& Wild, A.E. (Eds.), pp. 107-132. Cambridge, UK: Cambridge University Press.

\section{Proceedings Paper}

Wood, J.E., Williams, D.B. \& Goldstein, J.I. (1981). Quantitative X-ray microanalysis in the analytical electron microscope. In Quantitative Microanalysis with High Spatial Resolution, Jacobs, M.H., Lorimer, G.W. \& Doig, P. (Eds.), pp. 24-33. London: The Metals Society.

Tables. Tables must be uploaded individually at the website. Number tables consecutively using Arabic numbers and include concise titles and column headings. Type footnotes under the tables. All tables must be cited consecutively in the text.

\section{Guidelines for Figure Preparation}

Figures must be uploaded individually at the website. Figures should be professionally drawn and prepared according to the guidelines below. Symbols, letters, numbers, and scale bars should be of sufficient size to be clearly recognizable when the figure is reduced to publication size, usually one column width (84 mm). Figure captions must be double-spaced and appear on a separate page in the text document. All figures must be cited in the text. Photographs in which human subjects are identifiable must be accompanied by written permission for publication.

Note the following specifications:

- Black and white figures: Raster (scanned) images should be submitted in grayscale mode for continuous-tone images and as bitmaps for line art.
- Color figures: Color images should be submitted in CMYK color mode. Do not submit files in RGB color. Files should be free of color functions, including PostScript color management, transfer curves, halftone screen assignments, and black generation functions.

- Digital resolution: Raster (scanned) image files should be:

- at least 300 dpi for continuous tone images (grayscale or color);

- at least 900 dpi for monochrome (1-bit) line art.

- Image size/crop: Digital art files should be cropped to remove nonprinting borders. Lettering and axis labels for graphs should remain legible when reduced to an image width of $84 \mathrm{~mm}$. Letters within a word should not touch at this reduction. The submitted image orientation should be the same as intended for print.

- Lines: Lines or rules should not be defined as hairline width. The recommended minimum line width is $1 / 4$ point when the file is supplied at the same size as the final print; thicker lines must be used if the figure is to be reduced.

- File format: Rastered image files (continuous tone or line art) should be submitted only in ".tif", ".eps", or ".psd" format. For vector “.eps" or “.ai” files, fonts should be embedded or converted to outlines. Images should be flattened prior to submission; this means that files should not contain layers and/or transparent objects.

- Submission: Each figure must be uploaded separately from the text document of the manuscript.

Printed color figures. If you will not be paying to have your figures printed in color, your figures can still be in color in the electronic version of the paper. However, for the printed figure you must supply a grayscale monochrome version that can be completely understood without the need of color. Contrast adjustments may be necessary before submitting the grayscale image or figure.

Permissions. All previously published material included in your manuscript must be accompanied by permission forms or letters documenting that permission has been obtained to reprint the material in your article in this journal.

Submitting a manuscript to this journal is easy. Just go to the following website:

$$
\text { http://mc.manuscriptcentral.com/mam }
$$

Once at the login page, you will be asked to register with a User ID and password. Your manuscript can be submitted by the following seven simple steps displayed at the site. A help menu in orange (upper right) provides several ways to get support if you have difficulty. 


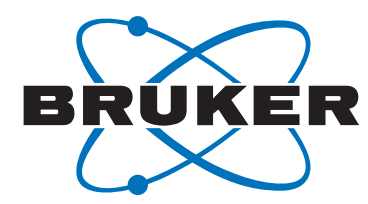

\section{EDS and EBSD for Nanoscience}

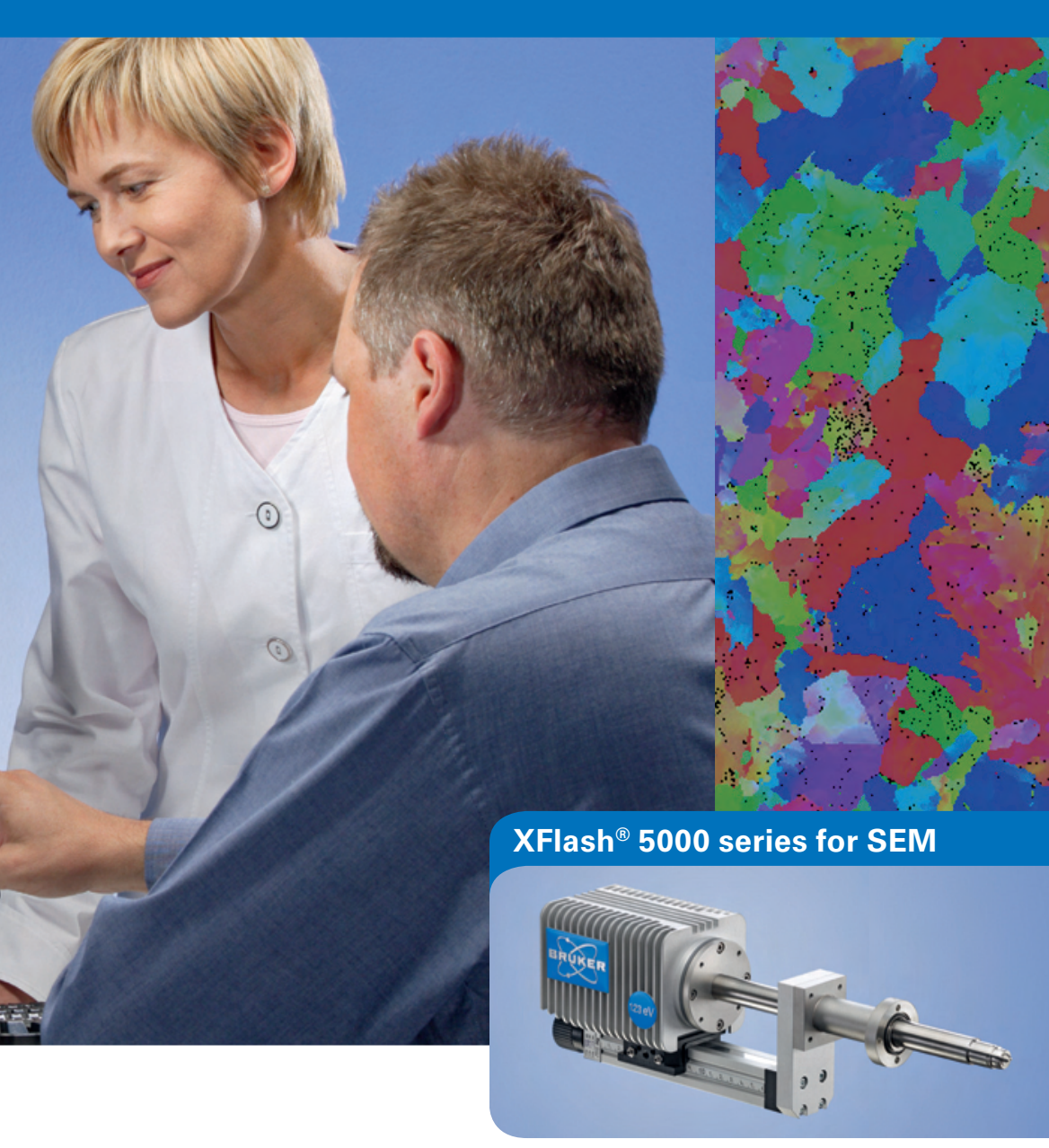

\section{QUANTAX EDS for SEM}

- Unique ESPRIT TQuant software for quantification at low acceleration voltages ( $<5 \mathrm{kV}$ )

- Unmatched resolution at all energies ( $M n$ K $\alpha \leq 123$ eV, F K $\alpha \leq 54$ eV, C K $\alpha \leq 46 \mathrm{eV}$ )

\section{QUANTAX EDS for S/TEM}

- Low weight, LN $\mathrm{N}_{2}$-free, large solid angle XFlash ${ }^{\circledR} \mathrm{SD}$ Detector

- Optimum performance in conventional and Cs-corrected S/TEM

\section{QUANTAX CrystAlign for EBSD}

- High-speed indexing of 880 patterns/s (730 patterns/s simultaneous EBSD/EDS acquisition)

- Colored SEM images for better grain differentiation using forescattered electron detectors

- NEW dynamic simulation of diffraction patterns

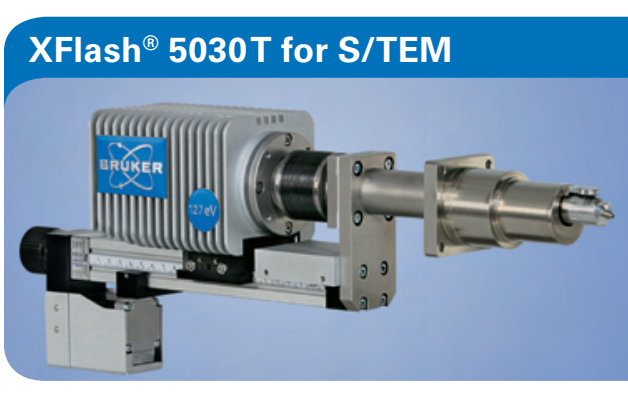

$e^{-}$Flash $^{1000+}$ EBSD Detector

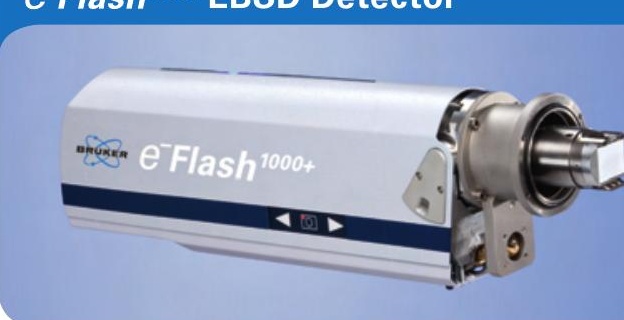

\section{www.bruker.com/microanalysis}

Innovation with Integrity 